\title{
Rapid virological response of telaprevir and boceprevir in a Brazilian cohort of HCV genotype I patients: a multicenter longitudinal study
}

This article was published in the following Dove Press journal:

Therapeutics and Clinical Risk Management

10 January 2017

Number of times this article has been viewed

\section{Helena HL Borba' \\ Astrid Wiens' \\ Laiza M Steimbach' \\ Fernanda S Tonin' \\ Maria LA Pedroso ${ }^{2}$ \\ Cláudia AP Ivantes ${ }^{3}$ \\ Fernando Fernandez- \\ Llimos $^{4}$ \\ Roberto Pontarolo'}

'Pharmaceutical Sciences Postgraduate Research Program, Department of Pharmacy, ${ }^{2}$ Gastroenterology Service, Hospital de Clínicas, Federal University of Paraná, ${ }^{3}$ Guidance and Counseling Center, Curitiba City Hall, Curitiba, Paraná, Brazil; ${ }^{4}$ Department of Social Pharmacy, Faculty of Pharmacy, Research Institute for Medicines, University of Lisboa, Lisbon, Portugal
Correspondence: Roberto Pontarolo Department of Pharmacy, Federal University of Paraná, Campus III, Prefeito Lothário Meissner Avenue, 632, Jardim Botânico, Curitiba, Paraná 80210-I70, Brazil

Tel +55 4I 33604094

Email pontarolo@ufpr.br
Background: Chronic hepatitis $\mathrm{C}$ is a major public health issue, but there is a gap in the literature regarding the effectiveness and safety of direct-acting antiviral agents in the Brazilian population. The main aim of this study was to describe the effectiveness of boceprevir and telaprevir in patients treated at public health care institutions in Brazil.

Materials and methods: A prospective longitudinal and multicenter study was conducted in five centers in the State of Paraná between September 2014 and June 2016. Data regarding effectiveness and safety were collected from medical records of patients treated with boceprevir or telaprevir. The effectiveness outcome comprised the rapid virological response (RVR). Multivariate analysis was performed to verify the influence of independent variables (ie, age, gender, baseline viral load) on RVR achievement.

Results: Data were collected from 117 patients with chronic hepatitis C virus (HCV) genotype 1 infection. Fifteen patients received treatment with boceprevir and 102 received telaprevir. The mean age was 51.6 years, $64.1 \%$ were male, $44.4 \%$ were infected with HCV subtype 1a, $62.4 \%$ had a high baseline viral load $(\geq 800,000 \mathrm{IU} / \mathrm{mL})$ and $33 \%$ were cirrhotic. Furthermore, $79.5 \%$ of patients achieved RVR $(26.7 \%$ in the boceprevir group and $87.3 \%$ in the telaprevir group). Multivariate analysis demonstrated that the type of protease inhibitor (boceprevir or telaprevir) and the baseline viral load had an influence on the RVR rate (odds ratio $[\mathrm{OR}]=0.011$; 95\% confidence interval [CI]: 0.001-0.119; $P<0.001 / \mathrm{OR}=13.004 ; 95 \% \mathrm{CI}: 1.522-111.115$; $P=0.019$, respectively).

Conclusion: In this longitudinal multicenter cohort study conducted from the Brazilian perspective, differences were found in the RVR rates, favoring telaprevir over boceprevir for genotype $1 \mathrm{HCV}$-infected patients. In addition, the baseline viral load was associated with RVR achievement in both evaluated groups. As RVR is also reported in the literature as a predictor of the sustained virological response (SVR), further analyses of RVR as predictor of SVR outcomes should be further evaluated in Brazil.

Keywords: hepatitis C, rapid virological response, protease inhibitors, telaprevir, boceprevir, multicenter

\section{Introduction}

With about $3 \%$ of the global population infected with the hepatitis $\mathrm{C}$ virus $(\mathrm{HCV})$, chronic hepatitis $\mathrm{C}$ is currently considered the leading cause of end-stage liver disease and liver transplantation worldwide. ${ }^{1,2}$ Genotype 1 is the most common among HCV genotypes, and it is responsible for about 83 million cases globally ( $46 \%$ of all hepatitis $\mathrm{C}$ events). ${ }^{3-5}$ Worldwide, about 4 million people are infected with $\mathrm{HCV}$ annually. ${ }^{6}$ In Brazil, it is estimated that about 2 million people are chronically infected 
with HCV, with 16,000 new cases of hepatitis C officially reported in 2014. However, only 20,000 infected patients are diagnosed in the country annually. ${ }^{7,8}$

As a major public health issue, the eradication of $\mathrm{HCV}$ is the main goal of pharmacological treatment and is measured by the sustained virological response (SVR), ie, undetectable serum HCV RNA 12-24 weeks after the end of treatment. ${ }^{9-11}$ The rapid virological response (RVR), defined as undetectable serum HCV RNA after 4 weeks of treatment, is an important predictor of SVR. ${ }^{12}$

Boceprevir and telaprevir, which target the viral serine protease NS3/4A, were the first direct-acting antiviral agents approved by the US Food and Drug Administration (FDA) for the treatment of chronic hepatitis C. ${ }^{13}$ With the advent of these first-generation protease inhibitors, SVR rates increased by $30 \%$ in comparison with the standard double therapy with polyethylene glycol-modified (pegylated) interferon (PegIFN) and ribavirin. ${ }^{14}$ Boceprevir and telaprevir were approved by the Brazilian Health Surveillance Agency (ANVISA) and incorporated in the public health system in 2012 to be used only by patients monoinfected with HCV genotype $1 .{ }^{15}$ Despite the approval of new direct-acting antivirals (ie, simeprevir, sofosbuvir and daclatasvir), ${ }^{16}$ boceprevir and telaprevir are still in use. However, an evident gap exists in the literature about the effectiveness and safety of these agents in the Brazilian population. Thus, the aim of this study was to describe the effectiveness outcomes related to the use of the first-generation protease inhibitors in addition to double therapy with PegIFN and ribavirin in patients treated at public health care institutions in Brazil.

\section{Materials and methods}

\section{Study design}

We conducted a prospective longitudinal and multicenter study in five centers of four cities in the State of Paraná (Cascavel, Maringá, Londrina and Curitiba), between September 2014 and June 2016. Data regarding effectiveness (virological response) and safety (adverse events and drug discontinuation) were collected from the medical records of patients with genotype $1 \mathrm{HCV}$ infection in triple therapy with either boceprevir plus PegIFN and ribavirin or telaprevir plus PegIFN and ribavirin. This study was conducted according to the Declaration of Helsinki and the Ethics Committee on Human Research of the Hospital de Clínicas - UFPR (Curitiba, Paraná, Brazil) approved the study protocol (Number 736.348). All participants provided written informed consent. The eligibility criteria followed the Brazilian guidelines for treating chronic HCV genotype 1 patients with first-generation protease inhibitors. Thereby, eligible patients comprised patients monoinfected with $\mathrm{HCV}$ genotype 1, those with advanced liver fibrosis (Meta-analysis of Histological Data in Viral Hepatitis [METAVIR] ${ }^{17}$ F3 or F4), METAVIR F2 nonresponders to previous treatments, those without decompensated cirrhosis or those using triple therapy with either boceprevir or telaprevir. Patients on double therapy only with PegIFN plus ribavirin, coinfected with other viral diseases (ie, HIV, hepatitis B), presenting signs of hepatic decompensation, or with any contraindication to the use of telaprevir or boceprevir were excluded.

\section{Data collection}

Information collected included sociodemographic data, data regarding previous treatments for chronic hepatitis $\mathrm{C}$ (treatment-naïve or treatment-experienced patients), comorbidities (ie, diabetes, systemic arterial hypertension), fibrosis stage according to the METAVIR score, ${ }^{17} \mathrm{HCV}$ genotype subtype (1a, $1 \mathrm{~b}$ or 1 undetermined), laboratory tests (hemoglobin, neutrophil count, platelet count, alanine aminotransferase [ALT] level, aspartate aminotransferase [AST] level), RNA viral load (for pretreatment and follow-up at weeks 4, 12,24 and 48 of treatment and at 24 weeks after the end of treatment), and adverse events (all side effects reported on the medical records during the treatment period, such as pruritus and cutaneous rash, were collected). In addition, data regarding treatment discontinuation and the reason leading to the withdrawal were also gathered. To avoid the effect of potential incompleteness of previous virological response data on medical records, treatment-experienced patients were not categorized as prior relapsers, prior partial responders or prior null responders. The participants were followed until 6 months after the end of treatment. A positive RVR was defined when the HCV RNA was "undetectable" at the fourth week of treatment. Patients missing HCV RNA data at this time were excluded from the analysis.

This study focuses on the RVR. Hence, all analyses herein presented are regarding this efficacy outcome.

\section{Statistical analysis}

Statistical analyses were conducted using IBM SPSS Statistics 24 (IBM Corp, Armonk, NY, USA), and a statistical probability less than 0.05 was considered to be indicative of significance. Categorical data are described as absolute and relative frequencies, and continuous data are shown as mean and standard deviation (for variables with a normal distribution) and as median and range (for variables with a non-normal distribution). For the univariate comparisons, 
categorical variables were analyzed by the Pearson's chisquared test and the continuous variables by Student's $t$-test or the Mann-Whitney test according to their normal or nonnormal distribution, respectively. The association between the categorical variables and the RVR rates was assessed by the Pearson's chi-squared test, and the Spearman Rank Correlation test was used for continuous variables. In order to measure the influence of several features related to the patient (eg, gender) and the disease (eg, fibrosis stage, HCV genotype subtype) on the RVR rate, we performed a binary logistic regression analysis.

\section{Results}

Data from 117 patients with chronic HCV genotype 1 infection were collected from the medical records of five centers in the State of Paraná. With respect to the baseline data, the mean age was 51.6 years $(\mathrm{SD}=9.5), 64.1 \%$ were male, $44.4 \%$ were infected with subtype 1 a of the virus, $62.4 \%$ had high baseline viral load ( $\geq 800,000 \mathrm{IU} / \mathrm{mL}$ ) with a median baseline viral load of $6.1 \log _{10} \mathrm{IU} / \mathrm{mL}$ and $33 \%$ were cirrhotic. Fifteen patients received treatment with boceprevir and 102 with telaprevir, $48.7 \%$ were treatment naïve, and $72.6 \%$ were prescribed PegIFN $\alpha-2 \mathrm{a}$ for the triple therapy. The characteristics of the participants distributed among the boceprevir and telaprevir groups differed significantly only regarding the HCV genotype subtype and the RVR rate. Details on the baseline data are presented in Table 1.

Regarding the RVR rate, 93 patients (79.5\%) achieved the virological response in the fourth week of treatment with the protease inhibitor, including four patients $(26.7 \%)$ in the boceprevir group and 89 patients $(87.3 \%)$ in the telaprevir group (Table 2).

Concerning the association between the variables gender, HCV subtype, previous treatment, PegIFN type, baseline polymerase chain reaction (PCR) (dichotomized as high or low), fibrosis stage, protease inhibitor (boceprevir or telaprevir) and RVR attainment, the Pearson's chi-squared test results revealed that only the protease inhibitor and the baseline PCR were associated with RVR achievement $\left(\chi^{2}\right.$ $P<0.001$ and $P=0.023$, respectively). With respect to the continuous variables age, baseline hemoglobin, baseline neutrophil count, baseline platelet count, baseline ALT,

Table I Baseline characteristics of the study patients

\begin{tabular}{|c|c|c|c|c|}
\hline Variables & BOC $(n=15)$ & TVR $(n=102)$ & $P$-value & Total $(\mathbf{N}=|| 7)$ \\
\hline Age, years; mean (SD) & $53.4(8.4)$ & $51.3(9.7)$ & 0.37 & $51.6(9.5)$ \\
\hline Gender, male; N (\%) & $12(80.0)$ & $63(61.8)$ & 0.17 & $75(64.1)$ \\
\hline HCV subtype; N (\%) & & & $0.03 *$ & - \\
\hline la & $2(13.3)$ & $50(49.0)$ & - & $52(44.4)$ \\
\hline $\mathrm{Ib}$ & $8(53.3)$ & $32(31.4)$ & - & $40(34.2)$ \\
\hline I & $5(33.3)$ & $20(19.6)$ & - & $25(21.4)$ \\
\hline Previous treatment, $\mathrm{n}(\%)$ & & & 0.47 & - \\
\hline Treatment naïve & $6(40.0)$ & $5 \mathrm{I}(50.0)$ & - & $57(48.7)$ \\
\hline Treatment experienced & $9(60.0)$ & $51(50.0)$ & - & $60(51.3)$ \\
\hline PegIFN type (prescribed for the TT), $n(\%)$ & & & 0.54 & - \\
\hline Alfa-2a & $10(66.7)$ & $75(73.5)$ & - & $85(72.6)$ \\
\hline Alfa-2b & $5(33.3)$ & $26(25.5)$ & - & $31(26.5)$ \\
\hline NR & $0(0.0)$ & I (I.0) & - & I (0.9) \\
\hline METAVIR score, n (\%) & & & 0.18 & - \\
\hline $\mathrm{FI}$ & $\mathrm{I}(6.7)$ & $\mathrm{I}(\mathrm{I} .0)$ & - & $2(1.7)$ \\
\hline F2 & $3(20.0)$ & $8(7.8)$ & - & II (9.4) \\
\hline F3 & $7(46.7)$ & $56(54.9)$ & - & $63(53.8)$ \\
\hline $\mathrm{F} 4$ & $4(26.7)$ & $35(34.3)$ & - & $39(33.0)$ \\
\hline NR & $0(0.0)$ & $2(2.0)$ & - & $2(1.7)$ \\
\hline HCV RNA & & & - & - \\
\hline$\geq 800,000 \mathrm{lU} / \mathrm{mL}, \mathrm{n}(\%)$ & $8(53.3)$ & $65(63.7)$ & 0.38 & $73(62.4)$ \\
\hline $\log _{10}$ IU/mL; median (range) & $5.9(2.3-6.6)$ & $6.1(3.7-7.0)$ & 0.24 & $6.1(2.3-7.0)$ \\
\hline Hemoglobin, g/dL; median (range) & $16.0(11.0-17.5)$ & $15.1(9.2-18.2)$ & 0.21 & $15.1(9.2-18.2)$ \\
\hline Neutrophil count $/ \mathrm{mm}^{3} ;$ median (range) & $2,944(1,500-5,212)$ & $3,060(1,239-7,455)$ & 0.90 & $3,056(1,239-7,455)$ \\
\hline Platelets, $\times 10^{4} / \mathrm{mm}^{3}$; median (range) & $14.5(7.7-44.8)$ & I6.I (5.4-34.5) & 0.52 & I6.I (5.4-44.8) \\
\hline ALT, IU/L; median (range) & $71.3(25.0-279.0)$ & $88.8(17.3-325.0)$ & 0.48 & $81.2(17.3-325.0)$ \\
\hline AST, IU/L; median (range) & $51.0(23.0-208.0)$ & $58.5(16.1-242.0)$ & 0.62 & $57.8(16.1-242.0)$ \\
\hline
\end{tabular}

Note: *Statistically significant.

Abbreviations: ALT, alanine aminotransferase; AST, aspartate aminotransferase; BOC, boceprevir; HCV, hepatitis C virus; METAVIR, Meta-analysis of Histological Data in Viral Hepatitis; NR, not reported; PegIFN, pegylated interferon; RNA, ribonucleic acid; RVR, rapid virological response; SD, standard deviation; TT, triple therapy; TVR, telaprevir. 
Table 2 RVR and changes in viral load after 4 weeks of treatment

\begin{tabular}{|c|c|c|c|c|}
\hline Variables & $\begin{array}{l}\text { Basal viral load, } \\
\text { IU/mL; mean (SD) }\end{array}$ & $\begin{array}{l}\text { Viral load at } 4 \text { weeks, } \\
\text { IU/mL; mean (SD) }\end{array}$ & $\begin{array}{l}\text { Viral load } \\
\text { difference, IU/mL }\end{array}$ & RVR, n (\%) \\
\hline BOC $(n=15)$ & $\begin{array}{l}1,326,915.67 \\
(1,349,599.78)\end{array}$ & $\begin{array}{l}34,462.73 \\
(43,540.10)\end{array}$ & $-1,292,452.94$ & $4(26.7)$ \\
\hline TVR $(n=102)$ & $\begin{array}{l}2,013,227.66 \\
(2,212,025.32)\end{array}$ & $\begin{array}{l}5,850.00 \\
(53,369.97)\end{array}$ & $-2,007,377.66$ & $89(87.3)$ \\
\hline$P$-value & $0.1 I^{\#}$ & $0.03^{\#, *}$ & - & $<0.00 I^{*}$ \\
\hline Total $(\mathrm{N}=117)$ & $\begin{array}{l}I, 922,923.45 \\
(2,126,851.25)\end{array}$ & $\begin{array}{l}9,518.30 \\
(52,925.6 I)\end{array}$ & $-1,913,405.15$ & $93(79.5)$ \\
\hline
\end{tabular}

Notes: "Equal variances not assumed; *Statistically significant.

Abbreviations: BOC, boceprevir; RVR, rapid virological response; SD, standard deviation; TVR, telaprevir.

baseline AST and baseline viral load on RVR achievement, a significant correlation was found only for the baseline viral load (Spearman's rho $r_{\mathrm{s}}=0.203, P=0.030$ ). Multivariate analysis demonstrated that only the protease inhibitor and baseline viral load had influence on the RVR rate (odds ratio $[\mathrm{OR}]=0.011 ; 95 \%$ confidence interval $[\mathrm{CI}]: 0.001-0.119$; $P<0.001 / \mathrm{OR}=13.004 ; 95 \%$ CI: $1.522-111.115 ; P=0.019$, respectively). The results of the logistic regression are expressed in Table 3.

\section{Discussion}

Despite the recent approval of IFN-free regimens, which have demonstrated great efficacy in several clinical trials for the treatment of chronic hepatitis $\mathrm{C}$, many patients still have limited access to these new agents. ${ }^{18-20}$ Therefore, studies addressing less-expensive therapies, which are still in use in several countries, are needed.

Table 3 Logistic regression to identify the influence of features related to the patient and the disease on RVR rates

\begin{tabular}{lllll}
\hline Variable & P-value & $\begin{array}{l}\text { Odds } \\
\text { ratio }\end{array}$ & \multicolumn{2}{l}{$\begin{array}{l}\text { 95\% Cl for } \\
\text { Exp(B) }\end{array}$} \\
\cline { 4 - 6 } & & & Lower & Upper \\
\hline Protease inhibitor & $<0.001 *$ & 0.011 & 0.001 & 0.119 \\
Gender & 0.134 & 2.658 & 0.740 & 9.541 \\
HCV subtype & 0.792 & 1.110 & 0.512 & 2.406 \\
Previous treatment & 0.824 & 1.155 & 0.325 & 4.104 \\
PegIFN type & 0.252 & 0.404 & 0.086 & 1.905 \\
Baseline viral load (low/high) & $0.019 *$ & 13.004 & 1.522 & 111.115 \\
Fibrosis stage & 0.239 & 0.262 & 0.028 & 2.429 \\
Baseline hemoglobin & 0.270 & 1.296 & 0.818 & 2.052 \\
Baseline neutrophil count & 0.346 & 1.000 & 1.000 & 1.001 \\
Baseline platelet count & 0.075 & 1.000 & 1.000 & 1.000 \\
Baseline ALT & 0.165 & 0.987 & 0.968 & 1.006 \\
Baseline AST & 0.088 & 1.023 & 0.997 & 1.051 \\
Age & 0.556 & 0.981 & 0.921 & 1.045 \\
Baseline HCV RNA & 0.120 & 2.032 & 0.831 & 4.970 \\
\hline Notes & & &
\end{tabular}

Notes: *Statistically significant. $\operatorname{Exp}(B)=$ odds ratios for the predictors.

Abbreviations: $\mathrm{Cl}$, confidence interval; $\mathrm{HCV}$, hepatitis $\mathrm{C}$ virus; PegIFN, pegylated interferon; ALT, alanine aminotransferase; AST, aspartate aminotransferase; RNA, ribonucleic acid; RVR, rapid virological response.
To our knowledge, this is the first observational study evaluating the RVR rate promoted by the first-generation protease inhibitors, as well as the first multicenter study evaluating the effectiveness of these treatments on chronic hepatitis $\mathrm{C}$, conducted in a real-life environment in Brazil. Poordad et $\mathrm{al}^{21}$ described RVR as a new milestone in the treatment of chronic hepatitis $\mathrm{C}$ because it is a strong positive predictor of SVR and, along with baseline viral load, may contribute to the establishment of individualized treatments. Subsequently, the evaluation of RVR in observational and interventional studies was reported as a predictive factor of chronic hepatitis $\mathrm{C}$ treatment response. ${ }^{22,23}$

The results of our multivariate analysis showed that the baseline viral load had an influence on the RVR rate. A retrospective study conducted by Jensen et $\mathrm{al}^{24}$ in 2006 , aiming to identify the predictors of RVR and SVR in HCV genotype 1 patients, revealed that individuals with a low baseline viral load $(<600,000 \mathrm{IU} / \mathrm{mL})$ were more likely to achieve RVR than those with a higher PCR baseline. In addition, patients who achieved RVR were more likely to achieve SVR. ${ }^{24}$

Our results also indicate that the use of triple therapy with telaprevir was associated with a higher RVR rate when compared to triple therapy with boceprevir ( $87 \%$ vs $27 \%$, respectively). Bailly et a ${ }^{25}$ (the ANRS CO20-CUPIC study) evaluated whether RVR is predictive of SVR in a cohort of HCV genotype 1 cirrhotic treatment-experienced patients treated with telaprevir or boceprevir and reported that RVR achievement was almost twofold higher in telaprevir patients than in boceprevir patients ( $67 \%$ vs $36 \%$ ). In contrast, Belperio et a ${ }^{26}$ evaluated the effectiveness of first-generation direct-acting antivirals in a cohort of US Veterans Affairs patients and reported no statistical difference in the proportion of noncirrhotic treatment-naïve patients achieving RVR (58\% of the telaprevir group and $49 \%$ of the boceprevir group; $P=0.200$ ).

Concerning the results of clinical trials, in the ADVANCE study, ${ }^{27} 68 \%$ of treatment-naïve patients attained RVR 
with telaprevir, whereas in the REALIZE study, ${ }^{28} 57 \%$ of treatment-experienced patients achieved RVR. In the SPRINT-2 study, ${ }^{29}$ the RVR rate in previously untreated patients was $91 \%$ with boceprevir, much higher than the results of our observational study. Compared with our observational real-life study, it seems that clinical trials report slightly lower RVR rates for telaprevir, but much higher rates for boceprevir. These discrepancies form the basis of real-life treatment outcome evaluation-based effectiveness studies ${ }^{30}$ and should be taken into consideration when making formulary and reimbursement decisions, especially in public health care institutions.

Almeida et al $^{31}$ evaluated the SVR of triple therapy with telaprevir or boceprevir in a Brazilian tertiary public hospital. Their population comprised only 24 patients (12 on telaprevir and 12 on boceprevir) with baseline characteristics similar to our cohort, except for a higher number of treatment-experienced and cirrhotic patients $(79.0 \%$ and $54.2 \%$, respectively). Of the 12 patients treated with telaprevir, $11(91.7 \%)$ achieved RVR, which is similar to our rate of $87.3 \%$. The RVR results in the boceprevir group were not reported. ${ }^{31}$

Evidence regarding the influence of RVR on SVR achievement has emerged recently. Pearlman and Ehleben, ${ }^{32}$ in a randomized open-label trial held in 2014, demonstrated that both baseline viral load and RVR are important predictors of SVR. They hypothesized that patients with a low baseline viral load and who attain RVR after 4 weeks of treatment with PegIFN and ribavirin are more likely to achieve SVR, which may render the use of a protease inhibitor unnecessary. ${ }^{32}$ However, further analyses are required to demonstrate the predictive value of baseline viral load and RVR achievement on SVR rates in a cohort of Brazilian patients. The long-term safety profile of protease inhibitors is also an important aspect to be evaluated in real-life studies, because first-generation agents are associated with adverse events (cutaneous rash was found to be related to telaprevir treatment and dysgeusia and anemia were related to boceprevir treatment). ${ }^{33}$ Therefore, further analysis addressing the adverse events associated with these agents should be conducted.

As limitations, our study included an unbalanced proportion of patients regarding the protease inhibitor used. However, as a real-life study, these percentages represent the actual treatment selection in Brazil. Regardless, with these figures, we were able to identify statistical differences between the two groups of patients.

Our analysis confirms the predictive value of baseline viral load on RVR achievement with first-generation protease inhibitors. In contrast to clinical trials, we found differences in RVR rates in a real-life prospective Brazilian multicenter cohort study in favor of telaprevir compared with boceprevir for genotype $1 \mathrm{HCV}$-infected patients with advanced liver fibrosis. Further analyses regarding the SVR should be conducted in this context.

\section{Acknowledgment}

This work was supported by the Coordination for the Improvement of Higher Level Personnel (CAPES) Foundation and the Brazilian National Council for Scientific and Technological Development (CNPq).

\section{Disclosure}

The authors report no conflicts of interest in this work.

\section{References}

1. Hughes E, Bassi S, Gilbody S, Bland M, Martin F. Prevalence of HIV, hepatitis B, and hepatitis C in people with severe mental illness: a systematic review and meta-analysis. Lancet Psychiatry. 2016;3(1): 40-48.

2. Coilly A, Roche B, Duclos-Vallee JC, Samuel D. News and challenges in the treatment of hepatitis $\mathrm{C}$ in liver transplantation. Liver Int. 2016;36(suppl 1):34-42.

3. Gower E, Estes C, Blach S, Razavi-Shearer K, Razavi H. Global epidemiology and genotype distribution of the hepatitis $\mathrm{C}$ virus infection. J Hepatol. 2014;61(1 suppl):S45-S57.

4. Alkhouri N, Zein NN. Protease inhibitors: silver bullets for chronic hepatitis C infection? Cleve Clin J Med. 2012;79(3):213-222.

5. Messina JP, Humphreys I, Flaxman A, et al. Global distribution and prevalence of hepatitis C virus genotypes. Hepatology. 2015;61(1): $77-87$.

6. Kretzer IF, do Livramento A, da Cunha J, et al. Hepatitis C worldwide and in Brazil: silent epidemic - data on disease including incidence, transmission, prevention, and treatment. Scientific WorldJournal. 2014; 2014:827849.

7. Brazilian Ministry of Health. Boletim Epidemiológico - Hepatites Virais. Brazil: Secretary for the Vigilance on Health, Department of STD, AIDS and Viral Hepatitis, Brasilia, Ministry of Health; 2015.

8. Ferreira PR, Brandao-Mello CE, Estes C, et al. Disease burden of chronic hepatitis C in Brazil. Braz J Infect Dis. 2015;19(4):363-368.

9. Webster DP, Klenerman P, Dusheiko GM. Hepatitis C. Lancet. 2015; 385(9973):1124-1135.

10. Kau A, Vermehren J, Sarrazin C. Treatment predictors of a sustained virologic response in hepatitis B and C. J Hepatol. 2008;49(4):634-651.

11. Thornton K, Deming P, Manch RA, et al. Is response guided therapy dead? Low cure rates in patients with detectable hepatitis $\mathrm{C}$ virus at week 4 of treatment. Hepatol Int. 2016;10(4):624-631.

12. Federico A, Masarone M, Romano M, Dallio M, Rosato V, Persico M. Rapid virological response represents the highest prediction factor of response to antiviral treatment in HCV-related chronic hepatitis: a multicenter retrospective study. Hepat Mon. 2015;15(6):e18640.

13. Feeney ER, Chung RT. Antiviral treatment of hepatitis C. BMJ. 2014; 348:g3308.

14. Shahid I, WH AL, Hafeez MH, Hassan S. Hepatitis C virus infection treatment: an era of game changer direct acting antivirals and novel treatment strategies. Crit Rev Microbiol. 2016;42(4):535-547.

15. Brazilian Ministry of Health. Inibidores de Protease (Boceprevir e Telaprevir) para o tratamento da Hepatite Crônica C. Brazil: Secretariat of Science, Technology and Strategic Inputs. Department of Science and Technology, Brasília, Ministry of Health; 2012. 
16. Brazilian Ministry of Health. Simeprevir, sofosbuvir e daclatasvir no tratamento da hepatite crônica tipo C e coinfecções. Brazil: Secretariat of Science, Technology and Strategic Inputs. Department of Science and Technology, Brasília, Ministry of Health; 2015.

17. Bedossa P. Intraobserver and interobserver variations in liver biopsy interpretation in patients with chronic hepatitis C: the French METAVIR Cooperative Study Group. Hepatology. 1994;20(1):15-20.

18. Fabrizi F, Martin P, Cacoub P, Messa P, Donato FM. Treatment of hepatitis C-related kidney disease. Expert Opin Pharmacother. 2015; 16(12):1815-1827.

19. Rubin RA, Russo MW, Brown KA, et al. Twice-daily telaprevir for posttransplant genotype 1 hepatitis $C$ virus: a prospective safety, efficacy, and pharmacokinetics study. Exp Clin Transplant. Epub 2016 Nov 18.

20. de Bruijn W, Ibanez C, Frisk P, et al. Introduction and utilization of high priced HCV medicines across Europe; implications for the future. Front Pharmacol. 2016;7:197.

21. Poordad F, Reddy KR, Martin P. Rapid virologic response: a new milestone in the management of chronic hepatitis C. Clin Infect Dis. 2008; 46(1):78-84.

22. Cavalcante LN, Lyra AC. Predictive factors associated with hepatitis C antiviral therapy response. World J Hepatol. 2015;7(12): 1617-1631.

23. Yu ML, Dai CY, Huang JF, et al. Rapid virological response and treatment duration for chronic hepatitis $\mathrm{C}$ genotype 1 patients: a randomized trial. Hepatology. 2008;47(6):1884-1893.

24. Jensen DM, Morgan TR, Marcellin P, et al. Early identification of HCV genotype 1 patients responding to 24 weeks peginterferon alpha-2a (40 kd)/ribavirin therapy. Hepatology. 2006;43(5):954-960.
25. Bailly F, Virlogeux V, Dufour C, et al. Early virological assessment during telaprevir- or boceprevir-based triple therapy in hepatitis $\mathrm{C}$ cirrhotic patients who failed a previous interferon based regimen the ANRS CO20-CUPIC study. Clin Res Hepatol Gastroenterol. 2015;39(4):443-450.

26. Belperio PS, Hwang EW, Thomas IC, Mole LA, Cheung RC, Backus LI. Early virologic responses and hematologic safety of direct-acting antiviral therapies in veterans with chronic hepatitis C. Clin Gastroenterol Hepatol. 2013;11(8):1021-1027.

27. Jacobson IM, McHutchison JG, Dusheiko G, et al. Telaprevir for previously untreated chronic hepatitis $\mathrm{C}$ virus infection. $N$ Engl J Med. 2011;364(25):2405-2416

28. Zeuzem S, Andreone P, Pol S, et al. Telaprevir for retreatment of $\mathrm{HCV}$ infection. N Engl J Med. 2011;364(25):2417-2428.

29. Poordad F, McCone J Jr, Bacon BR, et al. Boceprevir for untreated chronic HCV genotype 1 infection. $N$ Engl J Med. 2011;364(13): 1195-1206.

30. Black N. Why we need observational studies to evaluate the effectiveness of health care. BMJ. 1996;312(7040):1215-1218.

31. Almeida PR, Fonseca CB, Koch VW, Souza AM, Feltrin AA, Tovo CV. Triple therapy in chronic hepatitis $C$ : initial series in a public health program in the South of Brazil. Arq Gastroenterol. 2015;52(1): 14-17.

32. Pearlman BL, Ehleben C. Hepatitis C genotype 1 virus with low viral load and rapid virologic response to peginterferon/ribavirin obviates a protease inhibitor. Hepatology. 2014;59(1):71-77.

33. Teixeira R, Nascimento Yde A, Crespo D. Safety aspects of protease inhibitors for chronic hepatitis $\mathrm{C}$ : adverse events and drug-to-drug interactions. Braz J Infect Dis. 2013;17(2):194-204.
Therapeutics and Clinical Risk Management

\section{Publish your work in this journal}

Therapeutics and Clinical Risk Management is an international, peerreviewed journal of clinical therapeutics and risk management, focusing on concise rapid reporting of clinical studies in all therapeutic areas outcomes, safety, and programs for the effective, safe, and sustained use of medicines. This journal is indexed on PubMed Central, CAS,

\section{Dovepress}

EMBase, Scopus and the Elsevier Bibliographic databases. The manuscript management system is completely online and includes a very quick and fair peer-review system, which is all easy to use. Visit http://www.dovepress.com/testimonials.php to read real quotes from published authors. 